\title{
Objeto de aprendizagem sobre diversidade humana
}

\author{
Viviane de Fatima Bartholo ${ }^{1}$, Eunice Correa Sanches Belloti ${ }^{1}$, Debora Anterio \\ Garcia $^{1}$, Gabriela Spagiani Ferrari ${ }^{1}$ \\ ${ }^{1}$ Faculdade de Tecnologia de Ourinhos (FATEC) \\ Av. Vitalina Marcusso, 1400 - CEP 19910 - 206 - Ourinhos - SP - Brazil \\ \{viviane.bartholo, eunice.belloti\}@fatecourinhos.edu.br, \\ \{debora.garcia, gabriela.ferrari\} efatec.sp.gov.br>
}

\begin{abstract}
Prejudiced attitudes in daily life become commonplace in today's society. Research carried out in 2009 by the Foundation Economic Research Institute (Fipe) points out that schools are the main environments where there are various forms of prejudice, among them the prejudice of people with disabilities, ethnic-racial, sexual orientation and gender. The aim of this piece of work is to develop an object of learning directed to the initial years that corresponds to the third childhood, to help and help children in the reduction of prejudice and in the understanding of human diversity. For the development of this project, we used the tools Visual Studio and Adobe Photoshop, and a methodology of development of learning objects available in the literature. These stages of analysis and design were successfully developed.
\end{abstract}

Resumo. Atitudes preconceituosas no cotidiano tornam-se comuns na sociedade atual. Pesquisa realizada, em 2009, pela Fundação Instituto de Pesquisas Econômicas (Fipe) aponta que as escolas são os principais ambientes onde existem diversas formas de preconceito, dentre eles o preconceito de pessoas com deficiência, étnico-racial, orientação sexual e de gênero. O objetivo deste trabalho é desenvolver um objeto de aprendizagem voltado para os anos iniciais que corresponde à terceira infância, para auxiliar e ajudar crianças na diminuição de preconceito e na compreensão da diversidade humana. Para o desenvolvimento deste projeto, foram utilizadas as ferramentas Visual Studio e Adobe Photoshop, e uma metodologia de desenvolvimento de objetos de aprendizagem disponível na literatura. Tais etapas de análise e projeto foram desenvolvidas com sucesso.

\section{Introdução}

Os anos intermediários da infância, também conhecido com a terceira infância, de 6 a 11 anos, é o momento no qual a escola entra na vida infantil como sendo a principal experiência desse estágio. Também é um período no qual há foco no desenvolvimento psicossocial, físico e cognitivo da criança. É a partir dessa fase que elas começam a ter grandes progressos no pensamento, em julgamentos morais, na leitura, escrita e na memória. É nesta etapa que as diferenças individuais se tornam cada vez mais evidentes (Papalia, Olds e Feldman, 2006).

Pesquisa realizada em 2009 com 501 escolas públicas do país, mais de 18,5 mil alunos, pais e mães, diretores, professores e funcionários entrevistados pela Fundação Instituto de Pesquisas Econômicas (Fipe), comprova que o preconceito atinge 99,3\% das escolas no Brasil. Preconceitos como étnico-racial, socioeconômico, com relação a 
VIII Congresso Brasileiro de Informática na Educação (CBIE 2019)

Anais do XXV Workshop de Informática na Escola (WIE 2019)

portadores de necessidades especiais, gênero, geração, orientação sexual ou territorial, são comuns no dia a dia, principalmente no ambiente escolar (Estado 2009).

Torres e Torres (2014), afirmam que, no período da terceira infância, a criança começa a desenvolver o raciocínio e a reflexão, além de começar a ter um maior convívio com as pessoas e a enfrentar a influência social.

Allport (1954), relata que, o preconceito é um julgamento baseado em decisões e experiências antecipadas. É uma antipatia baseada em generalização falha e inflexível, podendo ser sentido ou expresso.

Becel (2018), destaca a importância de conscientizar e ajudar as crianças a partir do seu ambiente escolar, para que elas cresçam sendo pessoas abertas a todos os tipos de cultura, entendendo que todos são iguais, e que não se deve distinguir pessoas por meio de rótulos, independentemente da cor, religião, classe social, sexo ou deficiência.

É na terceira infância que o preconceito começa a surgir, sendo uma atitude desfavorável em relação aos outros indivíduos, havendo um conjunto de comportamentos agressivos, normalmente maldosos. Em muitos casos é aplicado em vítimas que são incapazes de se defender e que acabam sofrendo com esse tipo atitude.

De acordo com Carneiro e Silveira (2014), um objeto de aprendizagem (OA) é qualquer mídia eletrônica que tem como função trazer informações para construção do conhecimento educacional.

Segundo Aguiar e Flôres (2014), objeto de aprendizagem corresponde a uma classificação de software educativo. Consiste em uma ferramenta de ensino que pode ser utilizada para aprendizagem de diversas áreas. Também é um excelente aliado do professor durante as aulas, tornando-a mais atraente e dinâmica para os alunos.

Junqueira (2014) diz que os Objetos de Aprendizagem se caracterizam por serem recursos composto de algumas características essenciais, como: autonomia, reusabilidade e customização.

Portanto, se a tecnologia está cada vez mais presente no âmbito escolar trazendo softwares e jogos educativos (pois as crianças podem demonstrar mais interesse de aprendizado quando envolve tecnologias), o desenvolvimento de um objeto de aprendizagem sobre a diversidade humana seria um meio de transmitir às crianças conhecimentos esclarecedores, estimulando o respeito e demonstrando a importância das igualdades e equidades de uma forma mais dinâmica através dos objetos de aprendizagem, possibilitando também uma maior autonomia.

Desse modo, o objetivo do trabalho é desenvolver por meio das etapas de análise e projeto, um objeto de aprendizagem sobre a diversidade humana para auxiliar o processo de ensino aprendizagem de alunos de anos iniciais, que corresponde à terceira infância, recomendado para a idade de 8 a 10 anos. É feito o recorte dessa idade em função das crianças estarem alfabetizadas.

Em pesquisas na literatura não foi encontrado nenhum objeto de aprendizagem com específico deste assunto. 
VIII Congresso Brasileiro de Informática na Educação (CBIE 2019)

Anais do XXV Workshop de Informática na Escola (WIE 2019)

\section{Método}

Para o projeto proposto, são utilizados os métodos de pesquisa bibliográfica e pesquisa descritiva. A linguagem de programação escolhida para ser utilizada neste projeto, foi C\#, que é uma linguagem simples e orientada a objetos. Para o desenvolvimento deste projeto, foram utilizadas as ferramentas Visual Studio 2017 e Adobe Photoshop.

Para o desenvolvimento de um objeto de aprendizagem de qualidade existe uma série de atividades propostas. Essas atividades precisam ser bem definidas e organizadas para que seja visível o aperfeiçoamento do trabalho da equipe envolvida.

A metodologia que será aplicada neste projeto, foi definida por Oliveira, Amaral e Bartholo (2010) que propõe uma metodologia dividida em quatro etapas, consistindo em análise, projeto, implementação e validação. A metodologia proposta segue uma abordagem evolutiva buscando melhorias desde a primeira etapa, até a última. Estas alterações devem ser incorporadas ao ciclo de vida do desenvolvimento.

A etapa de análise refere-se às atividades que antecedem os processos de modelagem e implementação. Nesta fase é definido o público-alvo e o conteúdo da proposta pedagógica. $\mathrm{Na}$ etapa do projeto são desenvolvidos os modelos que ajudarão na implementação. Esses modelos sugeridos pela metodologia são: mapa conceitual, mapa navegacional e storyboard. A fase de implementação é seguida conforme os storyboards. O software educacional é implementado com base em critérios de acessibilidade e usabilidade de modo que atinja o público-alvo. A validação é a etapa em que acontecerá a avaliação do objeto de aprendizagem por parte do público-alvo. Logo após a avaliação, são desenvolvidos os manuais dos usuários finais.

\section{Resultados}

Considerando a pesquisa da literatura sobre diversidade humana, terceira infância e objeto de aprendizagem, pode-se dar início ao desenvolvimento do projeto utilizando a metodologia proposta por Oliveira, Amaral e Bartholo (2010) para o desenvolvimento de objetos de aprendizagem.

Na primeira etapa Análise foram definidos o público-alvo que são crianças da terceira infância entre 8 a 10 anos. Também foi realizada uma análise sobre o assunto juntamente aos profissionais da área de Psicologia.

$\mathrm{Na}$ segunda etapa Projeto, foram desenvolvidos os storyboards e o mapa conceitual e navegacional.

Segundo Moreira (2012), mapas conceituais são diagramas de significados, que indicam relações entre conceitos. Podem possuir um modelo hierárquico, mas não implicam uma sequência, direcionalidade e nem hierarquias organizacionais. Neste projeto tem como objetivo apresentar a ideia que será aplicada no desenvolvimento do objeto de aprendizagem sobre a diversidade humana.

O mapa navegacional tem o objetivo de mostrar como será feita a navegação entre as telas. Apresenta um funcionamento semelhante a um Diagrama de Fluxo. O modo como as setas estão direcionadas demonstra como será feito o trajeto das telas, e dentro delas percebe-se os conteúdos que serão abordados (Cordeiro et al, 2007).

Storyboard é semelhante a uma história em quadrinhos. Representa cenas do roteiro a ser seguido na implementação em forma de desenhos sequenciais. Seu objetivo 
VIII Congresso Brasileiro de Informática na Educação (CBIE 2019)

Anais do XXV Workshop de Informática na Escola (WIE 2019)

é facilitar a visualização do produto, eventualmente diminuindo erros inesperados e tempo de produção (Vargas; Rocha; Freire, 2007).

Foi escolhido como forma de representar os storyboards, os protótipos de telas. $\mathrm{O}$ protótipo de tela do menu principal, conforme mostra a figura 1a, apresenta as opções de histórias, quiz, jogos e sair. Essas opções foram escolhidas com o intuito de entreter e prender a atenção da criança para melhor entendimento sobre o assunto.

Na opção "Histórias", será apresentado para as crianças os personagens, onde cada um apresentará uma característica especial, como demostrado na figura $1 \mathrm{~b}$ e $1 \mathrm{c}$.

Já na opção "Quiz", será apresentado perguntas relacionadas as histórias dos personagens e diversidade humana (figura 1d), e na opção "Jogos" estará disponível alguns jogos como caça-palavras e "cruzadinha", para o entretenimento e o auxílio na aprendizagem.

$1 \mathbf{a}$

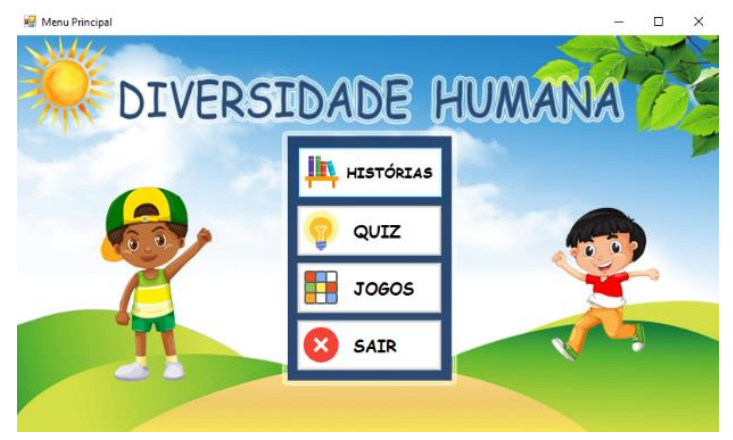

1c

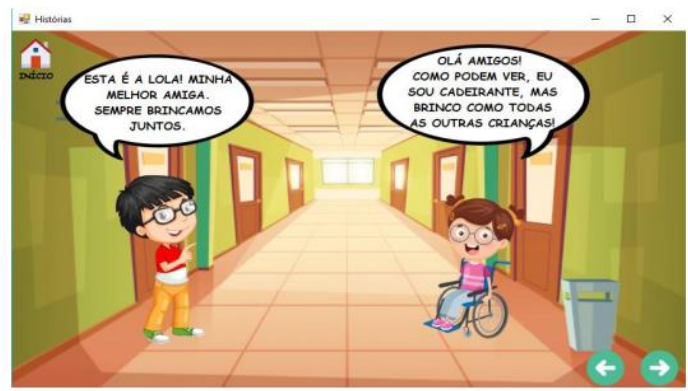

$1 \mathbf{b}$

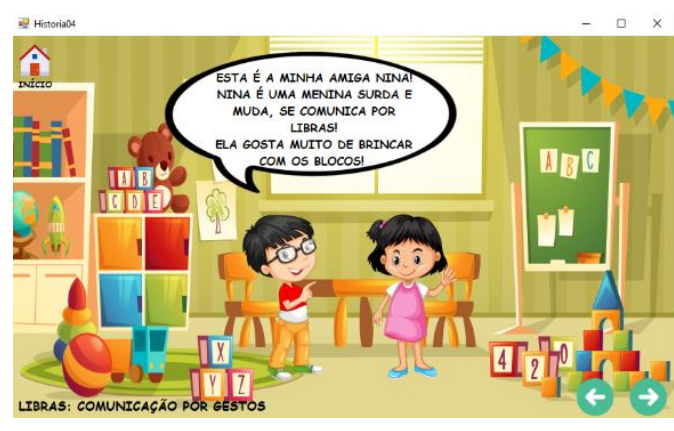

1d

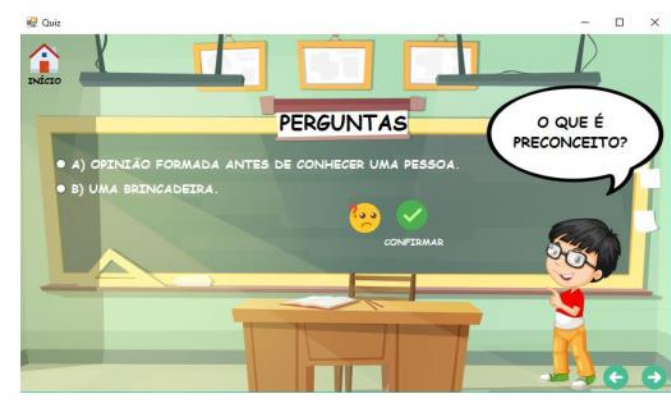

Figura 1a, 1b, 1c e 1d: Protótipos de tela

As próximas etapas da metodologia de desenvolvimento de objetos de aprendizagem utilizada, são a implementação e a validação.

\section{Considerações finais}

Até o momento o objetivo previsto para este trabalho foi alcançado, ou seja, foi possível identificar as necessidades do objeto de aprendizagem sobre a diversidade humana e desenvolver toda etapa de análise e projeto, gerando a documentação necessária para a aplicação das próximas etapas.

Para continuidade do trabalho, será realizada a implementação e os devidos testes de validação. 
VIII Congresso Brasileiro de Informática na Educação (CBIE 2019)

Anais do XXV Workshop de Informática na Escola (WIE 2019)

Ao finalizar o objeto de aprendizagem, espera-se contribuir para o processo de ensino sobre a diversidade humana.

\section{Referências}

Aguiar, E. V. B.; Flôres, M. L. P. (2014) Objetos de Aprendizagem: teoria e prática. 1. ed. Porto Alegre: Evangraf Ltda.

Allport, G. W. (1954). "The nature of prejudice", https://faculty.washington.edu/caporaso/courses/203/readings/allport_Nature_of_prej udice.pdf.

Becel, B. A. "Desigualdade Humana". (2018). https://www.webartigos.com/artigos/desigualdadehumana/157118.

Carneiro, M. L. F. e Silveira, M. S. (2014). “Objetos de Aprendizagem como elementos facilitadores na Educação a Distância.” Revista UFPR. Curitiba, v. 30, n. 4, p. 235260. https://revistas.ufpr.br/educar/article/view/38662/24346.

Cordeiro, R. A. C., et al. (2007) Utilizando mapas conceituais, de cenário e navegacional no apoio ao processo de desenvolvimento de objetos de aprendizagem. CINTEDUFRGS. Rio Grande do Sul, v. 5, n.1, p. 1-14, jul.

ESTADO, Agência. (2009) Pesquisa comprova que preconceito atinge 99,3\% do ambiente escolar no Brasil. Disponível em:

$<$ https://www.gazetadopovo.com.br/educacao/pesquisa-comprova-quepreconceitoatinge-993-do-ambiente-escolar-no-brasilbmg041fsqi54m $7 \mathrm{htmbm} 3 \mathrm{emm} 32 />$. Acesso em: 20 mai. 2019.

Junqueira, R. P. e Lóscio, B. L. (2014) "Repositórios de Objetos de Aprendizagem: uma análise comparativa com ênfase no reúso de conteúdos" In Anais do Simpósio Brasileiro de Informática na Educação (Vol. 25, No. 1, p. 988).

Moreira, M. A. (2012) Mapas conceituais e aprendizagem significativa. Porto Alegre. Disponível em: $<$ http://www.if.ufrgs.br/ moreira/mapasport.pdf $>$. Acesso em: 12 mai. 2019.

Oliveira, K. A.; Amaral, M. A. e Bartholo, V. F. (2010). "Uma experiência para definição de storyboard em metodologia de desenvolvimento colaborativo de objetos de aprendizagem". Ciências e Cognição. Paraná, v. 15, n. 1, p. 19-32. http://www.cienciasecognicao.org/revista/index.php/cec/article/view/279.

Papalia, D. E.; Olds, S. W. e Feldman, R. D. (2006). “Desenvolvimento Humano”. 8.ed. Porto Alegre: Artmed, 2006.

Torres, L. C. B. e Torres, F. M. (2014). "Etapas do Desenvolvimento Humano", https://www.agrinho.com.br/site/wp-content/uploads/2014/09/14_Etapas-dodesenvolvimento-humano.pdf.

Vargas, A.; Rocha, H. V.; Freire, F. M. P. (2007) Promídia: produção de vídeos digitais no contexto educacional. Revista RENOTE. Campinas, v. 5, n. 2.

Disponível em: <https://seer.ufrgs.br/renote/article/view/14199/8126>. Acesso em: 12mai. 2019. 